\title{
Challenges to adaptation: a fundamental concept for the shared socio-economic pathways and beyond
}

\author{
Dale S. Rothman • Patricia Romero-Lankao • \\ Vanessa J. Schweizer • Beth A. Bee
}

Received: 19 January 2013 / Accepted: 27 August 2013 / Published online: 27 September 2013

(C) The Author(s) 2013. This article is published with open access at Springerlink.com

\begin{abstract}
The framework for the new scenarios being developed for climate research calls for the development of a set of Shared Socioeconomic Pathways (SSPs), which are meant to differ in terms of their challenges to mitigation and challenges to adaptation. In order for the scenario process to fulfill its goals, the research and policy communities need to develop a shared understanding of these concepts. This paper focuses on challenges to adaptation. We begin by situating this new concept in the context of the rich literatures related to inter alia adaptation, vulnerability, and resilience. We argue that a proper characterization of challenges to adaptation requires a rich, exploration of the concept, which goes beyond mere description. This has a number of implications for the operationalization of the concept in the basic and extended versions of the SSPs. First, the elements comprising challenges to adaptation must include a wide range of socioeconomic and even some (non-climatic) biophysical factors. Second, careful consideration must be given to differences in these factors across scales, as well as cross-scale interactions. Third, any representation of the concept will require both quantitative and qualitative elements. The scenario framework offers the opportunity for the SSPs and full scenarios to be of greater value than has been the case in past exercises to both Integrated Assessment Modeling (IAM) and Impacts,
\end{abstract}

This article is part of the Special Issue on "A Framework for the Development of New Socio-economic Scenarios for Climate Change Research" edited by Nebojsa Nakicenovic, Robert Lempert, and Anthony Janetos

D. S. Rothman $(\bowtie)$

Frederick S. Pardee Center for International Futures, Josef Korbel School of International Studies, University of Denver, 2201 South Gaylord Street, Denver, CO 80208-0500, USA

e-mail: drothman@du.edu

P. Romero-Lankao

Urban Futures, National Center for Atmospheric Research (NCAR),

PO Box 3000, Boulder, CO 80307, USA

V. J. Schweizer

Integrated Science Program, National Center for Atmospheric

Research (NCAR), PO Box 3000, Boulder, CO 80307, USA

B. A. Bee

Department of Geography, Planning and Environment,

East Carolina University, Greenville, NC 27858, USA 
Adaptation, and Vulnerability (IAV) researchers, but this will require a renegotiation of the traditional, primarily unidirectional relationship between the two communities.

\section{Introduction}

Scenarios are important tools for understanding the long-term and complex interactions between human and earth systems. In this paper, we focus on the portion of the new scenarios for climate change research that describes socioeconomic change: the Shared Socio-economic Pathways (SSPs). These will later be combined with other elements related to climate forcing, climate changes, and climate policies to create scenarios for individual research projects and for integrated assessments of mitigation, adaptation, and residual climate impacts (Ebi et al. this issue; O'Neill et al. this issue; van Vuuren et al. this issue; Kriegler et al. this issue).

Recent proposals for a framework for the SSPs recommend exploring typologies of possible futures that differ in terms of their challenges to mitigation and challenges to adaptation (O'Neill et al. this issue). Additionally, in contrast to previous socioeconomic representations in climate change research (e.g. the SRES scenarios), the SSP framework intends to support the continued elaboration of the SSPs at more localized scales (the socalled "extended" SSP process as discussed in O'Neill et al. this issue) even after the basic versions of the SSPs are released. Furthermore, the goal is for the scenarios to be of value to both the Integrated Assessment Modeling (IAM) and Impacts, Adaptation, and Vulnerability $\left(\mathrm{IAV}^{1}\right)$ communities. In order for the overall SSP framework and process to be successful, developing a shared understanding of what is meant by socioeconomic challenges to mitigation and socioeconomic challenges to adaptation will be key.

This paper responds to this need by focusing on challenges to adaptation. First, we consider the concept in the context of existing literature and related ideas, such as vulnerability. This leads us to argue that a proper characterization of challenges to adaptation in the SSP framework can, and ultimately should, be very rich. Requiring, in the terminology of Geertz (1973), a 'thick' description, implies that we must go beyond a mere portrayal of challenges to adaptation to understand their contextual underpinnings. Second, we look at some particular implications this has for the operationalization of the concept. These relate to: the elements comprising challenges to adaptation; spatial and temporal aspects of challenges to adaptation; and the significance of both quantitative and qualitative representations of challenges to adaptation. Finally, we explore what this might mean for the use of the concept in both the current SSP process and beyond.

\section{Characterizing challenges to adaptation}

O'Neill et al. (this issue) describe challenges to adaptation as societal or environmental conditions, that, by making adaptation more difficult, increase the risks associated with any given level of climate change. There are several significant aspects of this description. First, in unpacking their description, O’Neill et al. (this issue) point to the varying and evolving definitions and interpretations of concepts such as vulnerability, which underpin the idea of challenges to adaptation. Second the inclusion of environmental conditions implies that other environmental factors are part of challenges to adaptation. This goes beyond earlier

\footnotetext{
$\overline{{ }^{1} \text { The acronym VIA is preferred by }}$ some researchers (see, for example, http://www.provia-climatechange.org).
} 
representations, e.g., in Arnell et al. (2011) and Kriegler et al. (2012), where these factors were not mentioned. Finally, the level of climate change is taken as given, implying that challenges to adaptation are not dependent on the actual level of climate change.

In the IPCC's Fourth Assessment Report (AR4), vulnerability is defined as "the degree to which a system is susceptible to, and unable to cope with, adverse effects of climate change, including climate variability and extremes. Vulnerability is a function of the character, magnitude, and rate of climate change and variation to which a system is exposed, the sensitivity and adaptive capacity of that system" (Parry et al. 2007, p. 883). In contrast, in the recent IPCC special report Managing the Risks of Extreme Events and Disasters to Advance Climate Change Adaptation (SREX), Cardona et al. (2012, p. 69-70) define vulnerability as "the propensity of exposed elements such as human beings, their livelihoods, and assets to suffer adverse effects when impacted by hazard events. . . Vulnerability is related to predisposition, susceptibilities, fragilities, weaknesses, deficiencies, or lack of capacities that favor adverse effects on the exposed elements."

The nuances here revolve around how different scholars parse their definitions to include or exclude the existence of hazards; the exposure to hazards; the sensitivity to hazards; and the ability to anticipate, reduce, prepare for, and respond to hazards. ${ }^{2}$ As such, the concept of vulnerability is deeply intertwined with related concepts including, but not limited to, hazards, risk, adaptation, ${ }^{3}$ adaptive capacity, ${ }^{4}$ coping capacity, and resilience (Janssen et al 2006; Gallopín 2006; Eakin and Luers 2006; Malone 2009; Turner 2010; Romero-Lankao and Qin 2011; Cardona et al. 2012; Romero-Lankao et al. 2013). It is beyond the scope of this paper to comprehensively review and parse the research and literature related to these concepts. Still, any characterization of challenges to adaptation must be built on the foundation they provide.

The most prominent interpretations of vulnerability for climate change research fall into two general categories, which go under a variety of names: (1) outcome, end-point, topdown or impact approaches and (2) contextual, starting-point, bottom-up or inherent approaches (O'Brien et al. 2007; Kelly and Adger 2000; Füssel 2009; Romero-Lankao et al. 2012). ${ }^{5}$ These are not simply different interpretations of the term vulnerability; they represent very different theoretical and practical framings of the climate change problem. As such, they have implications for how we characterize challenges to adaptation.

Outcome approaches consider vulnerability as the linear result, or net impact, of the projected impacts of climate change to an exposure unit (either social or biophysical) after

\footnotetext{
${ }^{2}$ Mathematically contrast the representation, $V=f(H, E, S, C)$, implied by Parry et al. (2007), where $V$ is vulnerability, $H$ is the hazard (climate change or variability), $E$ is exposure, $S$ is sensitivity, and $C$ is adaptive capacity with $R=f(H, E, V(S, C))$ implied by Cardona et al (2012), where $\mathrm{R}$ stands for risk and C includes a distinction between coping and adaptive capacity.

${ }^{3}$ AR4 defines adaptation as "actual adjustments, or changes in decision environments, which might ultimately enhance resilience or reduce vulnerability to observed or expected changes in climate" (Adger et al. 2007, 720). In other words, adaptations are specific actions that societies take to ameliorate the negative impacts of climate change or take advantage of the benefits. Yet, adaptation has also come to refer to the broader process by which societies respond to stressors that include, but are not limited to, climate change (Pielke et al. 2007; Adger et al. 2007).

${ }^{4}$ Increasingly attention to the concepts of adaptive capacity, or the ability of society to adapt, as well as to resilience, has shifted the discourse from a focus on adaptation as a technical or economic response to consider the broader constraints and opportunities that influence both the ability to adapt and the type of adaptation itself (Smit and Pilifosova 2001; Eakin and Luers 2006; Smit and Wandel 2006; Füssel and Klein 2006; Adger et al. 2007; Carter et al. 2007; Füssel 2007, 2009; O’Brien et al. 2007; Eakin et al. 2009; Ford et al. 2010; Romero-Lankao et al. 2012, 2013; Bee 2013).

${ }^{5}$ This division into two broad categories is, obviously, a simplification. McLaughlin and Dietz (2008) and Adger (2006) provide nice overviews of the range of perspectives on vulnerability.
} 
adaptation has taken place (O'Brien et al. 2007; Füssel 2007; Kelly and Adger 2000; Romero-Lankao and Qin 2011). The IPCC-AR4 definition of vulnerability generally reflects this framing (O'Brien et al. 2007; Füssel 2009; Parry et al. 2007). The outcome approach is seen in the many impact assessments that provide largely broad scale, scenario-driven estimates of the extent to which adaptation might reduce the adverse impacts of climate change (Smit and Wandel 2006; Füssel and Klein 2006; Carter et al. 2007). Some adaptive capacity is typically assumed (i.e. the ability to implement a given adaptation is not treated as a constraint in the analysis) and non-climatic (especially socioeconomic) factors are almost invisible in this framing. As a consequence, reducing outcome vulnerability focuses on reducing exposure or sensitivity through mitigation or technological adaptations to limit the negative outcomes of climate change (O'Brien et al. 2007; Füssel 2009).

In contrast, contextual approaches focus on increasing the capacity of individuals and groups to adapt, in large part by addressing the underlying causes of their vulnerability to the current climate (O'Brien et al. 2007). This framing is based on several approaches to climate-society interactions, including political economy and livelihoods that view vulnerability and adaptation as occurring within the context of political, institutional, economic, and social structures that shape both the process of adaptation and adaptive capacities, as well as the structural drivers creating differences in vulnerability among and within populations and systems of interest (O'Brien et al. 2007; Eakin and Lemos 2006). Important factors include: a) the demographic and socioeconomic characteristics of populations and their available assets; b) the capacity of populations to foresee, resist, react to, recover from, cope with, and take advantage of hazards and stresses; and c) the way in which governance and policies (e.g., infrastructure provision, health and education) influence those characteristics and adaptive capacities (Romero-Lankao and Qin 2011). To a much greater extent, this perspective showcases the role of non-climatic socioeconomic factors (O'Brien et al. 2004; Reid and Vogel 2006; Tschakert 2007; Westerhoff and Smit 2009; Ziervogel and Taylor 2008). Reducing contextual vulnerability, therefore, emphasizes existing vulnerabilities and reducing them through addressing the underlying processes and factors that determine exposure, sensitivity, and most importantly, adaptive capacity (Schipper 2007; Boyd et al. 2009; Jones and Boyd 2011).

Researchers have also argued for an approach that integrates the outcome and contextual perspectives (e.g., Turner et al. 2003; Ionescu et al. 2009; McEntire et al. 2010; RomeroLankao and Qin 2011). ${ }^{6}$ These scholars highlight the fact that human and earth systems are deeply intertwined, reflected in the use of the term socio-ecological systems, which originated in the resilience community. They point to the mechanisms by which socioeconomic and biophysical processes together shape vulnerability. This evolving perspective also places greater emphasis on how vulnerability plays out at, and across, multiple geographic and temporal scales.

In discussing challenges to adaptation, O’Neill et al. (this issue) also make reference to potential limits of autonomous adaptation, obstacles and constraints to adaptation policies, and potentially transformational technological progress. These concepts point to two other interrelated aspects of adaptation, which have been receiving increasing attention in the IAV community in recent years-limits to adaptation and whether adaptation is incremental or transformational. Both of these concepts are the subject of continuing discussion and clarification.

\footnotetext{
${ }^{6}$ This push for an integrated perspective on vulnerability is closely related to efforts to better integrate the resilience and vulnerability communities more generally (Gallopín 2006; Miller et al. 2010; Turner 2010)
} 
In Chapter 17 of AR4, Adger et al. (2007 p. 733) defined limits as "the conditions or factors that render adaptation ineffective." They used the terms barriers and limits somewhat interchangeably, discussing physical, ecological, and technological limits alongside financial, informational, cognitive, social, and cultural barriers. Subsequent scholarship has explored these ideas further, and tried to provide more clarity. In particular, there has been some effort to more clearly distinguish between barriers, which have been described as being "mutable, subjective, and socially constructed" (Adger et al 2009a, p. 338), and physical or ecological limits, which are more rigid and fixed (Adger et al 2009a; Hulme et al 2007; O’Brien 2009; Moser and Ekstrom 2010). Dow et al. (2013), adopting a risk framework, discuss limits to adaptation as forming a boundary between tolerable and intolerable risks. In a closely related vein, Preston et al. (2013) discuss the concept of a climate adaptation frontier. Dow et al. (203 p. 307) note that, "Some adaptation limits have been clearly identified, primarily for ecological systems, exemplified by species extinctions. But little is known about limits in social systems - whether there are social limits to adaptation, what influences their likelihood, where these might lie, who they would affect and what the consequences of reaching such limits might be."

The recognition of fixed limits requires us to consider the capacity for not only incremental adaptation, but potentially transformational adaptation, particularly when crossing thresholds leads to the irreversible loss of physical places or species of particular economic, cultural, or social significance and value. Both the vulnerability and resilience literatures originally focused on the ability of systems to resist or recover from stresses, although there was also some discussion of the ability to take advantage of opportunities. Over time, however, greater attention has been paid to the capacity for systems to undergo more fundamental changes due to climate change and other socioeconomic and biophysical stresses, either by desire or by necessity (O'Brien 2012). In recent IAV literature (Kates et al. 2012), the terms incremental and transformational adaptation are used to distinguish types of changes. In the resilience literature, the distinction is made between adaptability and transformability (Walker et al 2004; Folke et al. 2010).

This brief review on the recent literature related to vulnerability, hazards, risk, adaptation, adaptive capacity, and resilience points to the richness of challenges to adaptation. The broad allusions in the description of challenges to adaptation by O'Neill et al. (this issue) and elsewhere to "societal conditions" and "socioeconomic conditions", as well as the reference to constraints on adaptation, clearly point toward a view that shares more with the contextual than the outcome perspective on vulnerability. The recognition of the importance of (nonclimatic) biophysical processes, however, leads us to conclude that it needs to go even further to take a more integrated perspective that draws from both the outcome and contextual perspectives. One benefit of such an integrative approach to research is that it more clearly opens the door to insights related to scholarship on limits to adaptation and non-incremental adaptation. In the remainder of this paper, we explore what this means for operationalizing the concept and its implementation in the SSP process and beyond.

\section{Key Implications for operationalizing challenges to adaptation}

Operationalizing the concept of challenges to adaptation requires specifying relevant factors. O'Neill et al. (this issue) advance a candidate list, and van Ruijven et al. (this issue), explore this in some depth. Here we focus on a few key implications that fall out of our discussion in the previous section, which may be relevant for continued development of the SSPs, particularly the elaboration of "extended" versions. Specifically we emphasize the 
breadth of factors that would be relevant to include and the need to consider issues of geographical and temporal scale as well as the balance of factors that can and cannot be quantified.

The list of factors that are potentially relevant for specifying and describing challenges to adaptation is quite long. Füssel's (2007) typology of vulnerability factors is quite useful in thinking about what to include in such a list. He arrayed these factors across two dimensions: sphere (internal vs. external) and knowledge domain (socioeconomic vs. biophysical), yielding four categories:

- Internal socioeconomic: socioeconomic factors internal to the system of interest, e.g., income, social networks, access to information;

- External socioeconomic: socioeconomic factors that are external to the system of interest, but which provide the socioeconomic context in which it exists, e.g., national policies, international aid, and economic globalization;

- Internal biophysical: biophysical factors internal to the system of interest, e.g., topography, environmental conditions, and land cover; and

- External biophysical: biophysical factors that are external to the system of interest, but which provide the biophysical context in which it exists, e.g., severe storms, earthquakes, and sea-level change.

There is little or no dispute that internal socioeconomic factors belong to any characterization of challenges to adaptation in the SSP framework. The argument that a broad contextual interpretation is most appropriate implies that external socioeconomic factors are also relevant. This is supported by many IAV studies, where the ability of individuals and households to adapt to climate risks depends upon their access to certain resources, services, and options that can be constrained or enabled by various social, economic, and political institutions (Eakin and Lemos 2006; Smit and Wandel 2006; Osbahr et al. 2008; Adger et al. 2009b).

We also argue for the inclusion of biophysical factors, be they internal or external, in operationalizing the concept of challenges to adaptation. This reflects a growing trend to see socioeconomic systems as not existing in isolation from their physical environment. Exposure, sensitivity, coping, and adaptive capacity have important environmental dimensions (Cardona et al. 2012; O’Neill et al. this issue). Coastal areas, for example, are inherently more exposed to rising sea levels and storm surges than those areas further removed from the land-ocean interface. Societies that depend on rain-fed agriculture are particularly sensitive to changing patterns of precipitation. Other biophysical stressors, such as air pollution, will be aggravated by, and can aggravate the effects of, climate change. Finally, given that the availability of resources is one aspect of adaptive capacity, it would not make sense to dismiss the presence or absence of biophysical resources in characterizing challenges to adaptation.

Biophysical considerations are also relevant to the question of limits to adaptation, discussed in the previous section. Hulme et al. (2007, p. 1) refer to "thresholds of change in physical and ecological systems . . . beyond which irreversible change occurs." These biophysical thresholds work hand in hand with socioeconomic factors, including socioeconomic thresholds, to determine limits of adaptation.

In the SSPs, we have to be careful, though, about those biophysical factors that are directly climate related. O'Neill et al. (this issue) specify that the SSPs are part of a larger scenario framework that separates climate change, its impacts and climate policy responses. For this reason, climate-related biophysical factors would not be elements of SSPs. Of course, climate related factors cannot be ignored as we move beyond constructing the 
SSPs. Their later integration, once information from SSPs is combined with additional climate and policy information, is a point to which we will return to in the next section.

In addition to the need to consider the breadth of factors in operationalizing the concept of challenges to adaptation, any consideration must also pay attention to issues of scale. A recognition of spatial-temporal dimensions of vulnerability highlights the ways in which scale can influence a study's findings, where scale is defined as the spatial, temporal, or analytical dimension used by scholars to measure any phenomenon (Gibson et al. 2000). Through an examination of the relationships between multi-scalar socioeconomic influences on community vulnerability, Turner et al. (2003) uncovered multiple constraining and enabling influences that would escape detection had vulnerability been studied at only one scale. Others have highlighted how adaptation efforts at one scale may heighten or lessen challenges at other scales (Adger et al. 2005; McLaughlin and Dietz 2008). Eriksen and Kelly (2007), among others, also point to the importance of cross-scale interactions and potential teleconnections (Adger et al. 2008). Therefore, discerning challenges to adaptation at more aggregated spatial scales (e.g. national, global) may be less effective without information or representations of challenges to adaptation at more localized scales and vice versa. From a temporal perspective, a focus on the short-term might lead to overlooking long-term processes, while a focus on the long-term might lead to missing short-term triggers and opportunities for adaptation action (Romero-Lankao, et al. 2012). Finally, many vulnerability studies, particularly those using an outcome framing, tend to underscore factors related to sensitivity and adaptive capacity of populations as a whole, but overlook how the heterogeneity and structures of society (e.g., inequality and determinants of political power) relate to differences in vulnerability among different members of the population (RomeroLankao et al. 2012).

Taken together, the range of factors relevant to challenges to adaptation and the need to think about these across scales points to the need to include qualitative, and not only quantitative, indicators. Adaptive capacity and the limits to adaptation, and hence the process of adaptation, is influenced by socioeconomic, political, cultural, and psychosocial factors, such as access to financial capital, human capital, technology and information, infrastructure, institutions and entitlements, kinship networks, health and well-being, political capital, social capital, property rights, perceptions, attitudes, and power differentials (Adger et al. 2003, 2009a, 2012; Bee 2013; Brooks et al. 2005; Brouwer et al. 2007; Eakin and Lemos 2006; Ford et al. 2008; Reid et al. 2007; Moser and Ekstrom 2010; RomeroLankao et al. 2013; Smit and Pilifosova 2001; Yohe and Tol 2002). Many of these factors are not easily quantifiable, and therefore not discernible at aggregated scales. ${ }^{7}$ Still, a proper characterization of challenges to adaptation must include such difficult-to-quantify factors.

\section{Implications for the SSP process and beyond}

The characterization of challenges to adaptation and the need to consider a broad set of factors, both quantitative and qualitative, across multiple scales, has important implications for the SSP process and beyond. These, in turn, call for an evolution in the customary, primarily unidirectional relationship between IAM and IAV communities, i.e., where information from IAM runs is provided for use in IAV studies, with little feedback from the results of these studies back to future IAM efforts.

\footnotetext{
${ }^{7}$ Even in cases where a factor may be theoretically quantifiable, there may not be good, historical data and/or there may be limits to our ability to provide forecasts.
} 
The new scenario framework lays out a process with several phases (Ebi et al. this issue). This began with the development of Representative Concentration Pathways (RCPs). During a second, "parallel", phase in which socioeconomic information in the SSPs, climatic information based on the Representative Concentration Pathways (RCPs) and climate model runs, and Shared climate Policy Assumptions (SPAs) are developed separately from each other. The third, "integration" phase will bring together the RCPs, climate model results, SSPs, and SPAs to create coherent scenarios of the future accounting for specific climate policies, other socioeconomic developments, the resulting climate change, adaptations, and residual impacts.

In this framework, challenges to adaptation has a particular meaning for developing SSPs and refers only to those conditions that make adaptation more difficult in reference (or baseline) scenarios. In this regard, we have argued that challenges to adaptation shares much in common with a starting-point or contextual framing of vulnerability. Furthermore, it should go beyond traditional socioeconomic factors, such as those featured in the IPCC Special Report on Emissions Scenarios (Nakicenovic et al. 2000), to also consider other socioeconomic factors and (non-climatic) biophysical factors, as in the more integrated framings of vulnerability.

Of course, changes in biophysical conditions that are the result of climate change also pose challenges for adaptation. However, as discussed by O'Neill et al. (this issue), the SSPs serve a methodological (hypothetical/counterfactual) purpose, so the investigation of adaptation challenges directly related to different levels of climate change should occur only in the integration phase when using full scenarios (comprised of SSP, RCP, and SPA components) to explore issues related to mitigation, adaptation, and residual impacts.

The fact that both the contextual and integrated views of vulnerability are foundational to the SSPs signals a significant departure from the historically unidirectional relationship between the IAM and IAV communities. The SSPs cannot adequately describe socioeconomic challenges to adaptation unless they reflect the best available scholarship for what such challenges are. Thus IAV studies with a contextual or integrated framing are highly relevant for the SSPs as they are elaborated further into "extended" versions for more localized or sector-specific IAV studies. Moreover, as discussed previously, socio-ecologic challenges to adaptation are both scale-specific and subject to cross-scale influences. This further elevates the importance of a new generation of IAV studies that truly articulate challenges to adaptation. IAV research is already moving in this direction and combining different methods (syndrome-analysis, meta-analysis, comparative studies, and metaknowledge) to go beyond case studies to better understand the dynamics and interactions between climate hazards, exposure, sensitivities, adaptive capacities, and the determinants of each of these (Malone 2009; Romero-Lankao et al. 2012).

An additional implication of the new scenario framework is that a fundamental research need exists to close the iterative loop between the basic (global) versions of the SSPs, more detailed (localized and sector-specific) extended SSPs, and future assessments of adaptation challenges. Contributors to the development of the SSP process recognized that the basic, global versions of the SSPs needed to be sufficiently flexible to permit multi-scalar studies in order to be useful for IAV research. For example, van Vuuren et al. (2012a, p. 24) suggested that, "for many other 'vulnerability, impacts, and adaptation' studies, which seek to embed analysis of the potential robustness or performance of different locally-relevant adaptation strategies within the broader context of uncertain socio-economic or climate futures, it is better to use locally-derived scenarios reflecting development choices that can be embedded in broader 'bounding scenarios' of future global development and climate trends." We underscore here that it will not be enough to simply provide the IAV community the 
flexibility to customize basic SSPs - the iterative loop for SSPs must be closed such that extended or revised versions of the SSPs are re-evaluated with the scholarship of the IAV community as part of a comprehensive analysis of challenges to adaptation. ${ }^{8}$

Deeper thinking about IAV-IAM collaborations will be necessary to make such comprehensive analyses a reality. Already, the IAM community is working to develop integrated approaches for coupling their efforts to those who model climate and other biophysical earth systems (van Vuuren et al. 2012b). A similar effort is needed for the human dimensions of climate change (for a related discussion, see Schweizer and Bee 2013). This means that more effort is needed to incorporate socioeconomic factors that are currently rarely or inadequately addressed in IAMs (see also Patt et al. 2010). ${ }^{9}$

This collaboration needs to go beyond the enhancement of models, however. It will be difficult, if not impossible, to quantify many of the important factors related to challenges to adaptation. Therefore, it is important that the narrative components of the SSPs not be overshadowed by the quantification produced by the IAM community, which has been the case in many past exercises.

As the scientific community moves beyond the parallel phase to integrating the SSPs, RCPs, and other components (e.g., Shared Climate Policy Assumptions; see Kriegler et al. this issue), climatic factors themselves will intermix with the challenges to adaptation as defined in the SSPs. This will enable the full characterization of challenges to adaptation as laid out earlier in Sections 2 and 3. Research activities in SSP development and integration are ongoing but will certainly call for further collaboration between the IAM and IAV communities.

\section{Conclusions}

In this paper, we have unpacked the concept of challenges to adaptation, which along with challenges to mitigation, is being used to characterize the SSPs, one component of new scenarios for climate change research. First, we tried to situate this new concept in the context of the rich literatures related to inter alia adaptation, vulnerability, and resilience. This led us to argue that a proper characterization of challenges to adaptation requires a 'thick' description (Geertz 1973). This has a number of implications for the operationalization of the concept in the basic and extended versions of the SSPs. First, the elements comprising challenges to adaptation must include a wide range of socioeconomic and even some (non-climatic) biophysical factors. Second, careful consideration must be given to differences in these factors across scales, and ideally cross-scale interactions. Third, any representation of the concept will require both quantitative and qualitative elements.

The centrality of the concept of challenges to adaptation in the SSPs has deep implications for future climate research. We conclude that the traditional, primarily unidirectional relationship between the IAV and IAM communities must change in order to achieve two

\footnotetext{
$\overline{8}$ To provide an instructive example, objectives for the extended SSP process could be adopted that resemble the objectives of the World Water Scenarios developed as part of UNESCO's World Water Assessment Programme. One of their objectives includes, "Support scenario building at the national and subnational scales, which will inform the global process and stimulate the interchange of experiences, mutual learning and reciprocal capacity-building among ... interested groups" (UNESCO-WWAP 2012).

9 The call for IAM to incorporate additional socioeconomic factors should not be confused with asking the community to necessarily build ever more sophisticated models. As discussed by van Vuuren et al. (2012b), one can also think more critically about how to link IAM models' runs with analyses that are conducted by other researchers that use different tools.
} 
major objectives. First, more sophisticated thinking about the IAV-IAM interface is required to better bridge the often more local scale and shorter-time horizon studies of IAV with the generally larger-scale and longer-time horizon studies of IAM. This will be necessary if the SSPs are to live up to the expectation that they reflect the best available knowledge on socioeconomic challenges to adaptation. Second, it will not be enough to simply provide the IAV community the flexibility to customize basic versions of the SSPs for more localized studies. O'Neill et al. (this issue) envision a sustained process, where the basic SSPs can be refined using knowledge gleaned from their extension to the local levels. A further iterative loop may be necessary when full scenarios (SSP + RCP + SPAs) are analyzed - to enable a more sophisticated understanding of adaptation challenges in light of particular levels of climate change. This will require researchers to continue to think innovatively about the SSPs and the scenarios. Only in this way will they attain their goal of providing value to both the IAM and IAV communities, which is needed for more comprehensive understandings of the possibilities for the mitigation of and adaptation to future climate change, as well as any residual impacts.

Acknowledgments The authors would like to thank 2 anonymous reviews, Matthias Garschagen, Barry Hughes, Tom Wilbanks, Kris Ebi, and Brian O'Neill for their suggestions that helped us improve the manuscript. The work of Patricia Romero-Lankao and Vanessa Schweizer at the National Center for Atmospheric Research is managed by the University Corporation for Atmospheric Research and supported by the National Science Foundation (NSF). Any opinions, findings and conclusions, recommendations or omissions expressed are those of the authors and do not reflect the views of NSF.

Open Access This article is distributed under the terms of the Creative Commons Attribution License which permits any use, distribution, and reproduction in any medium, provided the original author(s) and the source are credited.

\section{References}

Adger WN (2006) Vulnerability. Glob Environ Chang 16:268-281

Adger WN et al (2003) Adaptation to climate change in the developing world. Prog Dev Studies 3:179-195 Adger WN, Arnell N, Tompkins E (2005) Successful adaptation to climate change across scales. Glob Environ Chang 15:77-86

Adger et al (2007) Assessment of adaptation practices, options, constraints and capacity. In: Parry et al (eds) Climate change 2007: impacts, adaptation and vulnerability. Cambridge University Press, Cambridge, pp 717-743

Adger WN, Eakin H, Winkels A (2008) Nested and teleconnected vulnerabilities to environmental change. Front Ecol Environ 7(3):150-157

Adger WN et al (2009a) Are there social limits to adaptation to climate change? Clim Chang 93(3-4):335-354

Adger WN, Lorenzoni I, O'Brien K (eds) (2009b) Adapting to climate change: thresholds, values, governance. Cambridge University Press, Cambridge

Adger WN, Barnett J, Brown K, Marshall N, O’Brien K (2012) Cultural dimensions of climate change impacts and adaptation. Nat Clim Chang 3(2):112-117

Arnell N, Kram T, Carter T, Ebi K, Edmonds J, Hallegatte S, Kriegler E, Mathur R, O’Neill BC, Riahi K, Winkler H, van Vuuren D, Zwickel T (2011) A framework for a new generation of socioeconomic scenarios for climate change impact, adaptation, vulnerability and mitigation research. Scenario Framework Paper

Bee B (2013) Who reaps what is sown? A feminist inquiry into climate change adaptation in two Mexican ejidos. ACME 12(1):131-154

Boyd E, Grist N, Juhola S, Nelson V (2009) Exploring development futures in a changing climate: frontiers for development policy and practice. Dev Policy Rev 27(6):659-674

Brooks N, Adger NW, Kelly PM (2005) The determinants of vulnerability and adaptive capacity at the national level and the implications for adaptation. Glob Environ Chang 15:151-163 
Brouwer R, Akter S, Brander L, Haque E (2007) Socioeconomic vulnerability and adaptation to environmental risk: a case study of climate change and flooding in bangladesh. Risk Anal 27(2):313-326

Cardona OD, van Aalst MK, Birkmann J, Fordham M, McGregor G, Perez R, Pulwarty RS, Schipper ELF, Sinh BT (2012) Determinants of risk: exposure and vulnerability. In: Field CB, Barros V, Stocker TF, Qin D, Dokken DJ, Ebi KL, Mastrandrea MD, Mach KJ, Plattner GK, Allen SK, Tignor M, Midgley PM (eds) Managing the risks of extreme events and disasters to advance climate change adaptation field, a special report of working groups I and II of the intergovernmental panel on climate change (IPCC). Cambridge University Press, Cambridge, pp 65-108

Carter TR et al (2007) New assessment methods and the characterization of future conditions. In: Parry ML et al (eds) Climate change 2007: climate change impacts, adaptation, and vulnerability, chap 2. Cambridge University Press, Cambridge, pp 133-177

Dow K, Berkhout F, Preston BL, Klein RJT, Midgley G, Shaw MR (2013) Limits to adaptation. Nat Clim Chang 3(4):305-307

Eakin H, Lemos MC (2006) Adaptation and the state: Latin America and the challenge of capacity-building under globalization. Glob Environ Chang 16:7-18

Eakin H, Luers A (2006) Assessing the vulnerability of social-environmental systems. Annu Rev of Environ Resour 31:365-394

Eakin H, Tompkins EL, Nelson DR, Anderies JM (2009) Hidden costs and disparate uncertainties: trade-offs involved in approaches to climate policy. In: Adger WN, Lorenzoni I, O'Brien KL (eds) Adapting to climate change: thresholds, values, governance. Cambridge University Press, Cambridge, pp 212-226

Ebi KL, Hallegate S, Kram T, Arnell NW, Carter TR, Edmonds J, Kriegler E, Mathur R, O’Neill BC, Riahi K, Winkler H, van Vuuren DP, and Zwickel $\mathrm{T}$ (this issue) A new scenario framework for climate change research: background, process, and future directions

Eriksen S, Kelly P (2007) Developing credible vulnerability Indicators for climate adaptation policy assessment. Mitig Adapt Strateg Glob Chang 12(4):495-524

Folke C et al (2010) Resilience thinking: integrating resilience, adaptability and transformability. Ecol Soc 15(4):20. [online] URL: http://www.ecologyandsociety.org/vol15/iss4/art20/

Ford JD et al (2008) Climate change in the Arctic: current and future vulnerability in two Inuit communities in Canada. Geogr J 174:45-62

Ford JD et al (2010) Case study and analogue methodologies in climate change vulnerability Research. Wiley Interdiscip Rev Clim Chang 1(3):374-392

Füssel HM (2007) Vulnerability: a generally applicable conceptual framework for climate change research. Glob Environ Change 17:155-167

Füssel HM (2009) Review and quantitative analysis of indices of climate change exposure, adaptive capacity, sensitivity and impacts. Background note to the World Development Report. World Bank, Washington

Füssel HM, Klein RJ (2006) Climate change vulnerability assessments: an evolution of conceptual thinking. Clim Chang 75:301-329

Gallopín GC (2006) Linkages between vulnerability, resilience and adaptive capacity. Glob Environ Chang 16:293-303

Geertz C (1973) The interpretation of cultures: selected essays. Basic Books, New York

Gibson CC, Ostrom E, Ahn TK (2000) The concept of scale and the human dimensions of global change: a survey. Ecol Econ 32(2):217-239

Hulme $\mathrm{M}$ et al (2007) Limits and barriers to adaptation: four propositions. Tyndall Centre for Climate Change Research, Norwich, pp 1-7

Ionescu C et al (2009) Towards a formal framework of vulnerability to climate change. Environ Model Assess 14(1):1-16

Janssen MA, Schoon ML, Ke W, Börner K (2006) Scholarly networks on resilience, vulnerability and adaptation within the human dimensions of global environmental change. Glob Environ Chang $16: 240-252$

Jones L, Boyd E (2011) Exploring social barriers to adaptation: insights from Western Nepal. Glob Environ Chang 21:1262-1274

Kates RW, Travis WR, Wibanks TJ (2012) Transformational adaptation when incremental adaptations to climate change are insufficient. PNAS 109(19):7156-7181

Kelly PM, Adger WN (2000) Theory and practice in assessing vulnerability to climate change and facilitating adaptation. Clim Chang 47:325-352

Kriegler E et al (2012) The need for and use of socio-economic scenarios for climate change analysis: a new approach based on shared socio-economic pathways. Glob Environ Chang 22:807-822

Kriegler E, Edmonds J, Hallegatte S, Ebi KL, Kram T, Riahi K, Winkler H, van Vuuren DP (this issue) A new scenario framework for climate change research: the concept of shared climate policy assumptions 
Malone EL (2009) Vulnerability and resilience in the face of climate change: current research and needs for population information, Batelle Pacific Northwest Division, PNWD-4087, http://populationaction.org/ wp-content/uploads/2009/08/Malone resilience.pdf. Accessed 18 January 2013

McEntire D, Gilmore Crocker C, Peters E (2010) Addressing vulnerability through an integrated approach. Int J Disaster Resil Built Environ 1(1):50-64. doi:10.1108/17595901011026472

McLaughlin P, Dietz T (2008) Structure, agency and environment: toward an integrated perspective on vulnerability. Glob Environ Chang 18:99-111

Miller F et al (2010) Resilience and vulnerability: complementary or conflicting concepts. Ecol and Soc 15(3):11. [online] URL: http://www.ecologyandsociety.org/vol15/iss3/art11/

Moser SC, Ekstrom JA (2010) A framework for diagnosing barriers to climate change adaptation. PNAS 107(51):22026-22031

Nakićenović N et al (2000) Special report on emission scenarios. Cambridge University Press, Cambridge

O'Brien KL (2009) Do values subjectively define the limits to climate change adaptation? In: Adger WN, Lorenzoni I, and O'Brien KL (eds) Adapting to climate change: thresholds, values, governance. Cambridge University Press, Cambridge, p 164-180

O’Brien K (2012) Global environmental change II: from adaptation to deliberate transformation. Prog Hum Geogr 36(5):667-676

O'Brien K et al (2004) Mapping vulnerability to multiple stressors: climate change and globalization in India. Glob Environ Chang 14:303-313

O’Brien K, Eriksen S, Nygaard L, Schjolden A (2007) Why different interpretations of vulnerability matter in climate change discourses. Clim Policy 7:73-88

O’Neill BC, Kriegler E, Riahi K, Ebi K, Hallegatte S, Carter TR, Mathur R, van Vuuren DP (this issue) A new scenario framework for climate change research: the concept of shared socio-economic pathways

Osbahr HC, Twyman C, Adger WN, Thomas DSG (2008) Effective livelihood adaptation to climate change disturbance: scale dimensions of practice in Mozambique. Geoforum 39:1951-1964

Parry ML et al (eds) (2007) Contribution of working group II to the fourth assessment report of the intergovernmental panel on climate change. Cambridge University Press, Cambridge

Patt AG et al (2010) Adaptation in integrated assessment modeling: where do we stand? Clim Chang 99(3-4):383-402

Pielke RA Jr, Prins G, Rayner S, Sarewitz D (2007) Lifting the taboo on adaptation. Nature 445:597-598

Preston BL, Dow K, Berkhout F (2013) The climate adaptation frontier. Sustainability 5(3):1011-1-35

Reid P, Vogel C (2006) Living and responding to multiple stressors in South Africa-glimpses from KwaZulu-Natal. Glob Environ Chang 16(2):195-206

Reid H, Sahlén L, MacGregor J, Stage J (2007) The economic impact of climate change in Namibia: how climate change will affect the contribution of Namibia's natural resources to its economy. Environmental Economics Programme Discussion Paper 07-02. International Institute for Environment and Development, London

Romero-Lankao, Qin H (2011) Conceptualizing urban vulnerability to global climate and environmental change. Curr Opin Environ Sustain 3(3):142-149

Romero-Lankao et al (2012) Urban vulnerability and adaptation to the health impacts of air pollution and climate extremes in Latin American cities. In: Holt WG (ed) Urban areas and global climate change. Emerald Group Publishing Limited, Bingley, pp 247-275

Romero-Lankao P, Qin H, Dickinson K (2013) Urban vulnerability to temperature-related hazards: a metaanalysis and meta-knowledge approach. Glob Environ Chang 22(3):670-683

Schipper LF (2007) Climate change adaptation and development: exploring the linkages. In: Tyndall Centre Working Paper No. 107

Schweizer V, Bee B (2013) Nested scenario meta-analyses to systematically address individual and societal consequences of climate change. Paper presented at the Impacts World 2013, International Conference on Climate Change Effects, Potsdam

Smit B, Pilifosova O (2001) Adaptation to climate change in the context of sustainable development and equity. In: McCarthy JJ et al (eds) Climate change 2001: impacts, adaptation, and vulnerability. Cambridge University Press, Cambridge, pp 877-912

Smit B, Wandel J (2006) Adaptation, adaptive capacity and vulnerability. Glob Environ Chang 16(3):282-292

Tschakert P (2007) Views from the vulnerable: understanding climatic and other stressors in the Sahel. Glob Environ Chang 17:381-396

Turner BL (2010) Vulnerability and resilience: coalescing or paralleling approaches for sustainability science? Glob Environ Chang 20:570576

Turner et al (2003) Illustrating the coupled human-environment system for vulnerability analysis: three case studies. PNAS 100:8080-8085 
UNESCO-WWAP (2012) World water assessment programme: world water scenarios to 2050, exploring alternative futures of the world's water and its use to 2050. Accessed January 17, 2013: http:// www.unesco.org/new/en/natural-sciences/environment/water/wwap/world-water-scenarios/

van Ruijven BJ et al. (this issue) Enhancing the relevance of global shared socio-economic pathways for climate change impacts, vulnerability and adaptation research

van Vuuren DP et al (2012a) A proposal for a new scenario framework to support research and assessment in different climate research communities. Glob Environ Chang 22:21-35

van Vuuren DP et al (2012b) A comprehensive view on climate change: coupling of earth system and integrated assessment models. Environ Res Lett 7(2):024012. doi:10.1088/1748-9326/7/2/024012

van Vuuren DP, Kriegler E, O'Neill BC, Ebi KL, Riahi K, Carter TR, Edmonds J, Hallegate S, Kram T, Mathur R, Winkler H (this issue) A new scenario framework for climate change research: scenario matrix architecture.architecture

Walker B, Holling CS, Carpenter SR, Kinzig A (2004) Resilience, adaptability and transformability in socialecological systems. Ecol and Soc 9(2):5. [online] URL: http://www.ecologyandsociety.org/vol9/iss2/art5

Westerhoff L, Smit B (2009) The rains are disappointing us: dynamic vulnerability and adaptation to multiple stressors in the Afram Plains, Ghana. Mitig Adapt Strateg Glob Chang 14:317-337

Yohe G, Tol RSJ (2002) Indicators for social and economic coping capacity-moving toward a working definition of adaptive capacity. Glob Environ Chang 12(1):25-40

Ziervogel G, Taylor A (2008) Feeling stressed: integrating climate adaptation with other priorities in South Africa. Environ 50(2):32-41 